\title{
In-situ mineralogical characterization of sulphide inclusions in diamonds
}

\author{
Pamato M.G. ${ }^{1 *}$, Nestola F. ${ }^{1}$, Novella D. ${ }^{2}$, Pearson \\ D.G. ${ }^{3}$, STACHEL T. ${ }^{3}$ \\ ${ }^{1}$ Department of Geosciences, University of Padova, Italy \\ ("correspondance: martha.pamato@unipd.it) \\ ${ }^{2}$ Department of Biological, Geological and Environmental \\ Sciences, University of Bologna, Italy \\ ${ }^{3}$ Earth and Atmospheric Sciences, University of Alberta, \\ Canada
}

Among mineral inclusions in diamond, sulphides are the most abundant. Also, they are the keel tool for dating diamond formation given their high concentration of highlysiderophile elements. However, the mineralogical nature of these inclusions is not well understood, mainly due to the exsolution of the original, high temperature monosulphide solid solution (Mss) to $\mathrm{Fe}-$, $\mathrm{Ni}$ - and $\mathrm{Cu}$-rich endmembers during cooling, obscuring the original composition. This complex exsolution observed in sulphide inclusions in diamonds can also cause problems with $\mathrm{Re}-\mathrm{Os}$ age determinations if the whole inclusion is not extracted.

To overcome this issue, recently, sulphide inclusions have been homogenized at high temperature and controlled oxygen fugacity [1]. However, X-ray diffraction or Raman spectroscopy analyses, required to accurately identify the inclusion phases, and define their degree of crystallographic plus compositional homogeneity, have not been reported.

Here we combine for the first time a thorough nondestructive multi-technique characterization of sulphide inclusions in diamonds from the Victor Mine (Canada) with homogenization experiments and isotopic analyses. In particular, we report X-ray diffraction data of the sulphides before and after homogenization, confirming a change from a polycrystalline assemblage of pyrrothite, pentlandite and chalcopyrite to single-crystal Mss. The data are used to reconstruct the Mss' original bulk composition, define the true bulk isotopic ratios and document any difference in ReOs isotope systematics.

[1] McDonald, I. et al. (2017) Geochimica et Cosmochimica Acta 216, 335-357 